\title{
SER PROFESSOR NA PERSPECTIVA INCLUSIVA: Saberes, Fazeres e Compromissos em uma Tríade Formativa
}

\author{
Cláudia Terra do Nascimento Paz ${ }^{1}$ \\ Tásia Fernanda Wisch²
}

\begin{abstract}
RESUMO
Este estudo reflexivo foi construído com o intuito de problematizar a docência no contexto da educação brasileira, tratando especificamente de professores que atuam na sala de aula regular e que se encontram preocupados em qualificar suas práticas e que, ao mesmo tempo, buscam possibilidades para a concretização de uma educação na perspectiva inclusiva. Para tanto, propomos refletir sobre os saberes, os fazeres e os compromissos dos professores que atuam na perspectiva inclusiva, trazendo à tona a importância da formação docente para a discussão. Fundamentadas pelos estudos de Tardif (2002), López (2016) e Arroyo $(2013,2014)$, nossas reflexões estão assentadas no conceito de professor inclusivo, o qual é por nós entendido como aquele profissional que se assume como protagonista de sua ação docente e dos processos de aprendizagem de todos seus estudantes. Nessa direção, estruturamos nossas reflexões a partir de uma proposição de uma tríade formativa, a qual pressupõe a relação entre saberes, fazeres e compromissos, que ao se entrelaçarem constroem permanentemente o profissional inclusivo. Defende-se que cada elemento da tríade possui uma interdependência dos demais, da mesma forma que todos eles dependem da formação permanente e da experiência de cada professor, sendo esses processos individuais e coletivos ao mesmo tempo.
\end{abstract}

Palavras-chave: Docência; educação inclusiva; saberes e fazeres docentes.

BE A TEACHER IN AN INCLUSIVE PERSPECTIVE: KNOWLEDGE, PRACTICES AND COMMITMENTS IN A TRAINING TRIAD

\begin{abstract}
This reflective study was constructed with the aim of problematizing teaching in the context of Brazilian education, dealing specifically with teachers who work in the regular classroom and who are concerned with qualifying their practices and who, at the same time, are seeking possibilities for achieving truly inclusive education. Therefore, we propose to reflect on the knowledge, actions and commitments of teachers who work in an inclusive perspective, bringing to light the importance of teacher training for the discussion. Based on studies by Tardif (2002), López (2016) and Arroyo (2013, 2014), our reflections are based on the concept of inclusive teacher, which is understood by us as the professional who assumes as protagonist of his teaching and learning processes of all its students. In this direction, we structure our reflections from a proposal of a training triad, which presupposes the relationship between knowledge, actions and commitments, interconnected, composing the permanent construction of the inclusive professional. It is argued that each element of the triad is interdependent on the others, just as they all depend on the ongoing training and experience of each teacher, these processes being individual and collective at the same time.
\end{abstract}

Keywords: Teaching; inclusive education; knowledge and teaching practices.

RECEBIDO EM: 31/8/2021

ACEITO EM: 8/10/2021

\footnotetext{
1 Autora correspondente. Instituto Federal de Santa Catarina - IFSC, Campus Tubarão. Rua Deputado Olices Pedro de Caldas, no 480 Dehon. Tubarão/SC, Brasil. CEP 88704-296. http://lattes.cnpq.br/7396663493771975. https://orcid.org/0000-0001-8182-9264. claudia. paz@ifsc.edu.br

2 Colégio de Aplicação da Universidade Federal do Rio Grande do Sul - CAP/UFRGS. http://lattes.cnpq.br/6057161772828893. https://orcid. org/0000-0002-0356-6347.
} 


\section{INICIANDO A REFLEXÃO: A Educação Inclusiva, Compromisso de Todos}

Os processos inclusivos constituem um debate bastante recente no contexto educativo brasileiro. Foram as políticas públicas das últimas décadas que permitiram os principais avanços tanto no que se refere ao acesso dos estudantes público-alvo da educação especial à escola regular, quanto no investimento na formação docente e na qualificação dos espaços escolares para atender tais demandas.

Posto isso, conceber uma escola na perspectiva inclusiva implica compreender a educação como investimento, que exige um conjunto de recursos e ações voltadas à concretização desse paradigma educativo. Em consonância a esta premissa, também partimos do pressuposto de que é dentro dos muros das escolas e das universidades que as práticas inclusivas se efetivam, e, nessa direção, há a exigência do comprometimento institucional com vistas a assumir e concretizar ações para atender tais demandas.

Desse modo, pensar a inclusão escolar significa compreender aspectos mais amplos que envolvem ações governamentais e iniciativas próprias de cada contexto/instituição de ensino. No que diz respeito a essa discussão, as vertentes teóricas mais críticas apontam para o entendimento de que essa questão perpassa os próprios projetos político-pedagógicos, construídos dentro das instituições de ensino. Tais reflexões são destacadas por Rigo (2017) quando afirma que:

Há um conjunto de iniciativas e ações necessárias para construir condições favoráveis para que as crianças sejam matriculadas nas escolas e possam viver um processo de inclusão, o qual não depende delas, mas de todo um contexto que vai além da matrícula e do atendimento educacional especializado. Essas condições, inicialmente, são da própria escola e suas estruturas, sejam elas arquitetônicas e/ ou pedagógicas, porém serão muito mais eficazes se estiverem articuladas e forem decorrentes das políticas do órgão municipal de educação (p. 199-200).

Para esta autora, o processo de inclusão de um estudante com deficiência está atrelado a condições favoráveis para a sua aprendizagem, as quais foram negadas/negligenciadas ao longo da história da educação brasileira. Tais discussões podem ser encontradas nos estudos de Moysés (2014), ao abordar que as especificidades no processo de aprendizagem na escola foram transformadas em doença, seja pelos interesses de funcionamento da ciência, seja pela incompetência que temos em trabalhar com a diferença, nesse caso, com a diferença no processo de aprender. Assentados num modelo classificatório e segregador e, em alguma medida, homogeneizador de educação, muitas vezes esses sujeitos são marcados pela reprovação e pelo preconceito em circulação na sociedade e na própria escola. Esses são sujeitos que "conquistaram o direito de entrar pelos portões da escola, mas ainda não conseguiram, apesar de toda sua resistência, de sua teimosia em querer aprender, derrotar o caráter excludente da escola brasileira" (MOYSÉS, 2014, p. 9).

Nesse sentido, parece haver uma resistência que invisibiliza esses alunos, que muitas vezes não são considerados nos planejamentos de ensino e consequentemente nos métodos avaliativos. As premissas, no entanto, de uma perspectiva inclusiva implicam o extremo oposto disso, envolvendo a necessidade da escola de se preparar para 
receber todos os alunos, ajustando-se às demandas e necessidades dos indivíduos. Educar pela inclusão implica, portanto, um ajuste do institucional ao individual e não o contrário (MENDONÇA, 2015).

Entendemos que inclusão escolar significa o compromisso com a aprendizagem de todos os estudantes. Ou seja, a máxima de que, ou a inclusão é para todos, ou não é de fato inclusão, é a compreensão deste estudo a respeito do referido paradigma. $E$, neste contexto, a escola e os professores precisaram reinventar muitas de suas práticas (GUIMARÃES; NAGATOMY, 2021).

Nas palavras de Diniz-Pereira e Leão (2008, p. 9):

Trazidos para as escolas por meio de mudanças conjunturais e mobilizações sociais que forçaram as políticas educacionais a permitirem o acesso desses sujeitos "outros" à Educação Básica, os profissionais da educação, que também já não são os mesmos, se viram diante de uma realidade que aquela formação generalista e homogeneizada não responderia mais (será que em alguma vez chegou a responder?).

Assim sendo, o objetivo deste estudo está assentado na reflexão sobre os saberes, fazeres e compromissos docentes dos professores na perspectiva inclusiva, discutindo a importância da formação nesse contexto, mediante a proposição de uma tríade formativa. Ou seja, buscamos compreender a docência em tempos de inclusão.

Partimos do pressuposto de que ser professor é um contínuo processo de aprender, o qual, ao longo do exercício de sua prática, é mobilizado por múltiplos saberes. De acordo com Tardif (2002), esses saberes são construídos, reconstruídos e [re]significados durante a formação profissional e, também, durante o exercício da própria docência. Segundo o referido autor, os saberes dos professores podem ser definidos como um conjunto de conhecimentos provenientes de fontes variadas, que o autor relaciona em quatro categorias: saberes profissionais, disciplinares, curriculares e experienciais. Nesse conjunto de saberes, existem aqueles que são construídos por meio da prática docente, chamados de saberes experienciais, e aqueles que são construídos por intermédio da formação, chamados de saberes profissionais (TARDIF, 2002).

Neste estudo analisaremos os saberes profissionais e experienciais dos professores que atuam em uma perspectiva inclusiva, a partir de Tardif (2002). E, também, os fazeres e os compromissos desses professores, diante da profissão, do contexto da sala de aula regular e das diversidades no processo de aprendizagem, segundo López (2016). Nosso entendimento é de que o professor, quando assume seu papel diante da docência, tem responsabilidades para com a aprendizagem de todos os estudantes. Esse compromisso, no contexto das práticas inclusivas, demanda do professor determinados fazeres, que trarão maiores possibilidades de aprendizagem aos estudantes.

Assim sendo, este estudo está assentado na importância dos saberes docentes, dos fazeres docentes e do compromisso profissional, assumidos pelos professores. Esta tríade de elementos se constitui fundamental, pois como bem expõe López (2016), dizem respeito ao êxito e ao futuro da própria educação. 


\section{CAMINHOS METODOLÓGICOS}

Este é um estudo qualitativo, de ordem eminentemente teórica, de escrita reflexiva. Compreende-se que estudos reflexivos constituem-se de metodologias de coprodução de conhecimento, que permitem a valorização de diferentes saberes (SCHOMMER; FRANÇA-FILHO, 2006). Tais metodologias contribuem para a ampliação da aprendizagem crítica na formação acadêmica, ao demandarem um posicionamento crítico em relação aos conceitos teóricos, possibilitando o enfrentamento dos desafios educacionais (ALCADIPANI, 2011).

Esta escrita constituiu-se a partir de uma matriz de reflexão analítica, elaborada pelas autoras, e, portanto, definidos, a priori, como eixos de análise. Tais eixos geraram uma tríade formativa de análise, a saber: saberes, fazeres e compromissos. Esta tríade foi elaborada a partir do referencial teórico utilizado, principalmente pautado em Tardif (2002), López (2016) e Arroyo $(2013,2014)$. Nesse sentido, a matriz de análise ficou assim definida:

Figura 1 - Matriz de análise - tríade formativa do professor inclusivo

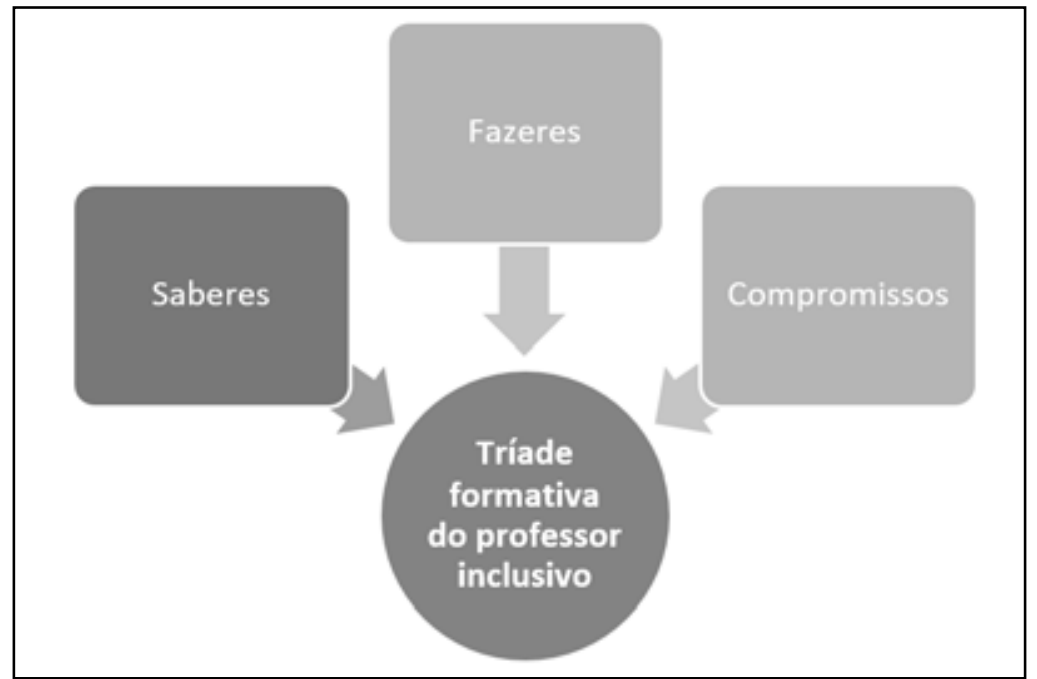

Fonte: As autoras (2021).

Nosso entendimento é o de que esses elementos, quando trazidos para a perspectiva da formação docente, possibilitam a compreensão da importância dos saberes, fazeres e compromissos dos professores diante da perspectiva inclusiva, que, ao serem assumidos pela escola brasileira, originam a reflexão teórica proposta pelas autoras neste estudo.

\section{A TRÍADE FORMATIVA DO PROFESSOR INCLUSIVO}

Optamos em nossas reflexões por utilizar a expressão "professor inclusivo" e cabe explicitarmos o sentido que essa terminologia carrega, neste contexto reflexivo. De forma alguma queremos afirmar que ser inclusivo é uma opção, como se o profissional pudesse escolher entre ser inclusivo ou não. Pelo contrário, o entendimento de professor inclusivo está relacionado com o compromisso ético que se assume ao escolher a profissão professor, ou seja, participar e mediar processos de aprendizagem de todos os estudantes. 
Em consonância a este entendimento, o professor é vislumbrado a partir de Freire (2013), que define a docência como uma profissão exigente, que implica um fazer ético e consciente sobre seu papel na vida de cada criança, jovem ou adulto, e que constrói sua prática pautada no respeito e na compreensão de que a educação é um direito de todas as pessoas.

Centradas nessa constituição, apresentaremos o professor como alguém que se constitui a partir da tríade formativa de professores inclusivos, definida, a priori, a partir dos autores escolhidos para compor a análise crítica. Para tanto, apresentamos a discussão acerca de cada elemento da tríade, trazendo os principais conceitos que estruturam o caminho teórico-reflexivo proposto.

\section{Quesaberes do Professor Inclusivo?}

Todos somos carregados de saberes e para tratar dos saberes do professor inclusivo fizemos a opção de adotar o conceito de saberes docentes de Tardif (2002), para o qual os saberes docentes compõem-se de saberes que são plurais, estratégicos e temporais em sua essência. "Pode-se definir o saber docente como um saber plural, formado pelo amálgama, mais ou menos coerente, de saberes oriundos da formação profissional e de saberes disciplinares, curriculares e experienciais" (TARDIF, 2002, p. 61).

Para este autor, os professores possuem múltiplos saberes. Ele elabora uma compreensão acerca da construção dos saberes dos professores, indicando-os como conhecimentos que se fundem e muitas vezes se contradizem, possibilitando o tensionamento de concepções e seus reflexos na ação pedagógica.

Tais estudos nos permitem inferir que os saberes profissionais respondem pelo conjunto de saberes científicos ou eruditos, que são transmitidos pelas instituições durante o processo de formação docente. Compõem os conhecimentos pedagógicos científicos, produzidos pelas chamadas ciências da educação. Já os saberes disciplinares, ou saberes das disciplinas, são aqueles que compõem os diferentes campos do conhecimento da formação de professores. Os saberes curriculares correspondem aos programas e currículos escolares que os professores devem aplicar. E, por fim, os saberes experienciais são aqueles que são aprendidos no exercício da profissão (TARDIF, 2002).

Também Gauthier (2013) define os saberes como "um repertório de conhecimentos próprios do ensino" (p. 35). Para este autor toda a prática docente é estabelecida a partir das construções que os professores vão produzindo ao longo da sua prática pedagógica. O que significa dizer que as escolhas, decisões e perspectivas teóricas estão assentadas nos sentidos que foram produzidos ao longo da sua trajetória, no exercício da profissão. Do mesmo modo, o autor ressalta que as representações da profissão se consolidam também em sala de aula e reitera que este processo não pode acontecer descolado de um movimento crítico sobre a educação como um todo e de um constante processo de reflexão sobre a prática (WISCH, 2020). 
Para mobilizar uma práxis inclusiva, portanto, os professores necessitam tanto dos saberes profissionais, disciplinares e curriculares, quanto dos saberes experienciais. $\mathrm{O}$ professor inclusivo se constitui ao longo da formação profissional, mas também precisa estar aberto a aprender com a própria experiência e com a experiência de outros, posto que é o contexto educativo que mobiliza os processos de aprender a fazer inclusão.

Dessa forma, os saberes experienciais são tomados como potencializadores do aprender a ser professor. Tardif (2002), ao refletir sobre estes saberes, destaca que todos os professores chegam à docência com conhecimentos prévios, construídos a partir de suas vivências como estudantes e a partir de outras experiências e, portanto, a inserção no campo de trabalho possibilita a consolidação ou ressignificação destes conhecimentos. O espaço da escola apresenta a estes profissionais o contexto dinâmico no qual o ensinar acontece de maneira sistematizada, e este lugar também se produz a partir das interações com os colegas, das realidades sociais e das demandas administrativas (WISCH, 2020). Ao se debruçar sobre estas reflexões, Tardif $(2002$, p. 53) afirma:

[...] a prática pode ser vista como processo de aprendizagem através do qual os professores reproduzem sua formação e adaptação à profissão, eliminando o que Ihes parece inutilmente abstrato ou sem relação com a realidade vivida e conservando o que pode servi-los de uma maneira ou de outra. A experiência provoca, assim, um efeito de retomada crítica dos saberes adquiridos antes ou fora da prática profissional.

E todas as construções que vão sendo delineadas neste percurso compõem os saberes da docência. Ou seja, estão relacionados a todo processo de constituição docente, que é contínuo e processual, está em permanente modificação, favorecendo a reconfiguração a partir dos contextos, das trajetórias e das reflexões produzidas ao longo da profissão.

Assim, os saberes disciplinares, os saberes curriculares e os saberes experienciais, abordados nos estudos de Tardif (2002), vão sendo apropriados pelos professores, e paulatinamente compõem um repertório que Ihes possibilita lidarem com as mais diversas exigências da profissão e, principalmente, estruturarem seus princípios e suas concepções acerca desta (WISCH, 2020).

Nas palavras de Tardif (2002, p. 106):

Saberes esses que não somente são adquiridos no e com o tempo, mas também temporais, pois são abertos, porosos, permeáveis e incorporam, ao longo do processo de socialização e da carreira, experiências novas, conhecimentos adquiridos durante esse processo e um saber-fazer remodelado em função das mudanças de prática e de situações de trabalho. Compreender os saberes dos professores é compreender, portanto, sua evolução e suas transformações e sedimentações sucessivas ao longo da história de vida e da carreira, história e carreira essas que remetem a várias camadas de socialização e de recomeços (TARDIF, 2002, p. 106).

Por mais que, no entanto, saibamos que ser professor é aprender cotidianamente, quando se trata da formação profissional há uma expectativa de que essa primeira etapa formativa seja capaz de dar conta de tudo, como se houvesse uma "receita pronta". Tardif (2002) ressalta que todos os saberes têm sua importância na constituição docente, contudo destaca que os saberes experienciais ocupam um importante papel 
como principais mobilizadores de aprendizagens, pois são os desafios diários, que nem sempre transcorrem da mesma forma como foi aprendido na academia, que colocam o professor diante da necessidade das tomadas de decisão e da elaboração de mediações para a sua resolução. Nesse sentido, o discurso da falta de formação necessita dar lugar para a busca constante pela formação e qualificação das práticas docentes. Imbernón (2010) enfatiza a necessidade e a importância dos professores se tornarem protagonistas de sua formação, compreendendo que o compromisso de busca e a ressignificação de seus saberes e fazeres é decorrente de um processo próprio de cada docente.

É fundamental reconhecer que a docência envolve medos e inseguranças. Esses sentimentos são muito verdadeiros quando estamos frente a frente com o desafio que é atuar em um contexto inclusivo. É nesse momento que os saberes profissionais, por meio da formação inicial e continuada, são entendidos como extremamente importantes.

A formação tem a função de nos oferecer conhecimentos preciosos sobre o fazer inclusivo, bem como pode mudar a forma como nos sentimos em relação à inclusão, permitindo-nos ver o que antes não víamos. E essa mudança de percepção necessita impactar em nosso compromisso profissional e possibilitar a reestruturação de nossos fazeres. Acreditamos, portanto, que os saberes docentes são constitutivos do professor inclusivo. O modelo de professor que pauta nossas reflexões pode ser entendido como aquele que

[...] deve conhecer sua matéria, sua disciplina e seu programa, além de possuir certos conhecimentos relativos às ciências da educação e à pedagogia e desenvolver um saber prático baseado em sua experiência cotidiana com os alunos (TARDIF, 2002, p. 67).

Desse modo, entendemos que o conceito de professor apresentado pelo autor é equivalente à compreensão a qual denominamos como professor inclusivo. Diante disso, a mobilização de determinados saberes, relativos à disciplina específica que leciona e temáticas mais gerais no âmbito da docência, associados à prática em sala de aula regular, possibilitam ao professor identificar as diversidades : presentes nesse ambiente e, com isso, as necessidades e especificidades no processo de aprendizagem.

Esse saber específico advém da formação e, também, da experiência, possibilitando que o professor identifique múltiplas demandas e necessidades individuais em sua sala de aula. Ser um professor inclusivo requer ser um observador constante. Requer também fazeres específicos, a partir da identificação das demandas individuais dos alunos, bem como uma postura ética e empática, como veremos a seguir.

\section{Quefazeres do professor inclusivo?}

Quando nos referimos a processos inclusivos, falamos de diversificação das práticas. É fundamental superar a ideia de que um único modelo de atividade e um único modelo de avaliação é capaz de contemplar todos os estudantes. Desse modo, falar sobre o fazer do professor passa pela compreensão de que seus alunos aprenderão de distintas maneiras e em diferentes ritmos. Assim, um professor inclusivo busca respeitar essas diferenças, bem como a trabalhar com elas. Ele passa a entender que jeitos e ritmos diferentes de aprender dos alunos são uma realidade concreta na sala de aula, 
o que, por muitas vezes, não combinam com os métodos de ensinagem tradicionais. Arroyo (2014) destaca que respeitar os tempos de aprendizagem é respeitar trajetórias humanas.

Por isso, o professor inclusivo necessita exercitar o desapego: desapego do velho plano de ensino, da velha ementa, dos velhos métodos de ensino e avaliativos. Incluir significa, às vezes, fazer novas escolhas metodológicas e avaliativas, que atendam a todos na sala de aula.

No contexto da docência, tanto os processos de aprender quanto os processos avaliativos são pontos de destaque para os professores, os quais se manifestam nas reflexões cotidianas acerca do espaço escolar. Muito tem se debatido no que diz respeito à compreensão de que o respeito e o olhar diferenciado precisam estar presentes diariamente em toda a organização da dinâmica pedagógica, isso porque ainda é necessário superar modelos baseados no domínio de conteúdos específicos da série. A perspectiva inclusiva remete a um modelo educativo que contempla a multiplicidade dos sujeitos, bem como a processualidade da construção das aprendizagens (PAZ; SOARES, 2018; WISCH, 2020).

Tais reflexões são apresentadas por Arroyo (2013) que em seus estudos, nos quais destaca importantes reflexões no contexto da avaliação, tendo em vista que nossas concepções ainda estão arraigadas em modelos que desconsideram os processos e os percursos individuais dos estudantes. Mesmo que, no campo do discurso, os professores defendam essa compreensão, na medida em que os estudantes avançam para os anos finais do Ensino Fundamental e do Ensino Médio, os professores retornam ao discurso dos conhecimentos relativos ao ano letivo/série, mostrando novas resistências (WISCH, 2020). Sobre este aspecto, Vygotski (2007) enfatiza que:

Embora o aprendizado esteja diretamente relacionado ao curso do desenvolvimento da criança, os dois nunca são realizados em igual medida ou em paralelo. $O$ desenvolvimento nas crianças nunca acompanha o aprendizado escolar da mesma maneira como uma sombra acompanha o objeto que o projeta. Na realidade, existem relações dinâmicas altamente complexas entre os processos de desenvolvimento e de aprendizado, as quais não podem ser englobadas por uma formulação hipotética imutável (p. 104).

Isso posto, os fazeres dos professores necessitam partir da compreensão de que os tempos e os ritmos de aprendizagem são elementos que atravessam a vida dos estudantes, e necessitam ser o ponto de partida das práticas docentes e, consequentemente, da avaliação.

É preciso, então, trabalhar em prol de um currículo mais generoso e flexível; uma trajetória que permita os múltiplos modos de aprender. "Esse processo inclui a preparação e a organização da própria instituição para ofertar educação de qualidade para todos, o que implica preparar-se para receber educandos com necessidades específicas de aprendizagem" (PAZ; SOARES, 2018, p. 53).

Ainda de acordo com Paz e Soares (2018), desse entendimento decorre que a inclusão não implica somente o acesso à vaga, mas, principalmente, um movimento em prol da permanência do estudante, por meio de ações institucionais que considerem as necessidades de adaptações às necessidades de aprendizagem do aluno. 
Uma possibilidade para dar conta dessa demanda é mediante o desenho universal de currículo, o qual vem desafiando os professores a construírem currículos capazes de contemplar os diferentes perfis de estudantes. Essa perspectiva teórica enfatiza que é preciso compreender que não somente os estudantes público-alvo da educação especial se beneficiam de currículos mais flexíveis, mas todos os que integram a sala de aula.

Os estudos de Pletsch, Souza e Orleans (2017, p. 274) indicam que:

O desenho universal aplicado à aprendizagem favorece a elaboração de um conjunto de estratégias, técnicas e materiais e recursos para garantir a participação dos alunos nos processos educativos, pois se entende que cada sujeito é único e responde de forma única às oportunidades pedagógicas. Em outros termos, a proposta do desenho universal na aprendizagem sugere o acesso e a garantia da aprendizagem a todos os alunos presentes no contexto escolar, a partir do oferecimento de múltiplas e variadas formas de organizar e disponibilizar os conhecimentos científicos.

E dentro das proposições de currículo adaptado podemos trazer como exemplo o Plano Educacional Especializado - PEl. De acordo com Ulliane (2016), o PEI é uma ferramenta, um recurso pedagógico, com foco no aluno, que possibilita a organização curricular individualizada, permitindo o acompanhamento de cada discente. Sobre esse Plano é importante salientar que:

O PEI é um documento de grande importância, já utilizado em outros países, como a Itália e diversos Estados dos Estados Unidos. Nesses locais, o PEI caracteriza-se como um instrumento garantido por lei e obrigatório em todos os níveis, inclusive na educação superior. Na Itália, o modelo de PEI é direcionado para o aluno com deficiência e estabelece os objetivos mínimos de aprendizagem que devem ser alcançados pelo discente, garantindo-lhe o direito de receber um diploma regular (SONZA; SALTON; DALL AGNOL, 2018, p. 29).

Em síntese, consiste em uma documentação institucional de tudo que será proposto e desenvolvido para o estudante dentro de sua trajetória escolar. Esta proposição envolve a discussão e diálogo de estratégias institucionais elaboradas objetivamente para determinado estudante. Este documento também permite a construção do respeito ao desenvolvimento processual das aprendizagens. Ou seja, proporciona ao professor expressar seu compromisso para com a aprendizagem de todos.

\section{Quais Compromissos do Professor Inclusivo?}

Falar dos compromissos do professor inclusivo implica falarmos sobre as transformações ocorridas na escola, demandadas pelo paradigma da educação inclusiva. Nas palavras de López (2016, p. 111):

O contexto social e as mudanças nas exigências profissionais provocaram o desenvolvimento do conceito de compromisso como uma construção complexa e multidimensional que está muito marcada pelas características individuais. Parte do compromisso docente é associada ao interesse pelo próprio desenvolvimento profissional, sendo concretizado nos processos de aprendizagem dos professores, na sua vinculação com as instituições, no desejo de ser docentes ou no envolvimento com as crianças. Essa aprendizagem é, ao mesmo tempo, complexa e deslocada e 
tem múltiplas possibilidades, sendo a formação permanente uma delas, ainda que esta nos remeta a um conceito definido pela própria legislação educativa como um direito e uma obrigação de todos os professores.

Isso posto, o professor que se envolve com a perspectiva inclusiva necessita de formação permanente, buscando fundamentar sua atuação em uma identidade docente alicerçada na concepção de educação como um direito universal. Ou seja, possibilitar ao professor a construção do comprometimento com sua atuação docente também é um processo que se aprende, individual e coletivamente, por meio de processos formativos formais e informais, no seio da própria escola. As pesquisas realizadas por Rigo (2017, p. 209) destacam a docência no contexto da educação inclusiva:

Vemos muitos professores envolvidos e dispostos a tornar a escola um espaço social capaz de contribuir para a promoção de mudanças na sociedade, acreditando que pela sua capacidade de educar podem construir um outro mundo, com menos exclusões e mais inclusões. A experiência que se produz com o outro a partir da inclusão é uma possibilidade para que outras relações entre as pessoas possam se constituir; que as configurações tão consistentes entre a anormalidade e a normalidade, ou seja, entre o sujeito dito "anormal" e o "normal", possam ser questionadas e produzam reflexões que levem a uma nova ética da alteridade.

A partir dos estudos de Rigo (2017) podemos inferir que o compromisso com a perspectiva inclusiva também pode ser compreendido como a responsabilidade com a construção da cidadania e de uma sociedade mais justa. A contemporaneidade exige o compromisso com um lugar melhor e mais acolhedor. E, mais uma vez os saberes docentes fazem-se necessários, sejam eles os saberes profissionais ou experienciais.

Outro ponto fundamental das discussões propostas por Tardif (2002) situa-se na compreensão da temporalidade, ou seja, todos os saberes docentes são carregados das histórias vividas e de tudo que foi experimentado ao longo da carreira profissional, sem desconsiderar os tempos, espaços e os momentos históricos.

Assim, é durante o processo de construção da própria identidade profissional que os professores constroem também a percepção de seus compromissos profissionais, o que inclui a percepção para com a educação inclusiva. Tratando sobre a identidade profissional, Castra (2010, p. 72) afirma que:

A identidade profissional está constituída pelo conjunto de características e de atributos que fazem com que um indivíduo ou um grupo se percebam como uma entidade específica e que são percebidos como tal pelos outros. Este conceito deve ser aprendido na articulação de numerosas instâncias sociais, sejam estas individuais ou coletivas (Tradução nossa).

Esse é um processo que perpassa, inicialmente, pelo desejo e pela escolha de ser professor, como observa López (2016, p. 109):

A escolha de ser professor é fortemente determinada por elementos pessoais e subjetivos, biográficos e coletivos e, principalmente, por um senso de compromisso que se mantém e modifica durante o exercício da profissão e que, além das políticas formativas, continua sendo a base para o desenvolvimento e o aperfeiçoamento profissional. A paixão por ensinar, a dedicação de tempo fora do horário letivo, 
o envolvimento com os meninos e as meninas e a participação nas instituições de ensino configuram, junto com a ideologia e o envolvimento com os temas de índole social, uma concepção multidimensional do compromisso profissional docente.

Ou seja, é diante da escolha de ser professor que nasce a consciência para com os compromissos éticos, deontológicos e ontológicos. Quando falamos, aqui, em compromissos do docente inclusivo, estamos nos referindo à compreensão trazida por López (2016), a qual considera "compromisso" uma qualidade que distingue aqueles professores que desejam ser professores daqueles que se tornaram professores por outros motivos, que não necessariamente o desejo, o querer ser. Nas palavras do autor:

O compromisso é considerado como a qualidade que separa aqueles que "querem" ou "se entregam" daqueles "que não se preocupam com as crianças" ou "põem sua comodidade em primeiro lugar". Além disso, é também a característica que separa "aqueles que levam o trabalho a sério" daqueles que "não se preocupam com o que pode reduzir a qualidade" (LÓPEZ, 2016, p. 111).

Com outras palavras, também Mayo e Tardif (2018, p. 52) afirmam que "quando os novos papéis se estabilizam, se produz uma transformação da identidade profissional" (tradução nossa). Ou seja, a partir da formação inicial e das primeiras experiências, constrói-se a identidade docente e, a partir dela, o querer, o desejar, o comprometer-se.

Esta não é tarefa fácil ou simples. Nem sempre os professores conseguem de imediato assumirem-se como protagonistas dos processos educativos, pois é preciso aceitar o novo, o desconhecido, o desacomodar-se.

Pesquisando sobre o antagonismo existencial ${ }^{3}$ de professores do Ensino Médio da rede estadual de um município de Minas Gerais, em relação à educação inclusiva, Paz e Cruz (2021) observaram que, de início os professores estavam angustiados e desconfortáveis com o processo de educação inclusiva. À medida, contudo, que iniciaram o trabalho e tiveram contato com os alunos, essas percepções mudaram para posturas mais empáticas e profissionais. Nesse sentido, a formação continuada exerceu papel decisivo, pois pôde dirimir o antagonismo existencial e fortalecer a identidade docente, de forma a proporcionar suporte às práticas pedagógicas.

Por essas razões, entendemos que a perspectiva inclusiva passa por posturas de empatia, acolhimento e ética, pois o compromisso da escola é também o compromisso de cada um que escolhe ser professor. É preciso colocar-se no lugar do outro. Nesse caso, de um outro que possui percursos diferenciados de construção de aprendizagens.

\section{APONTAMENTOS FINAIS}

Partimos do pressuposto de que a história de cada pessoa vai sendo tecida a partir de suas vivências e experiências e, de um modo geral, a trajetória escolar faz parte deste percurso. Para as crianças e adolescentes a escola faz parte de todo o seu de-

De acordo com Cunha e Cintra (2001), o antagonismo existencial pode ser compreendido como um sentimento de oposição ou ausência de compatibilidade de opiniões e de perspectivas. 
senvolvimento e se traduz em um espaço de aprendizagem. Para os professores, além de remeter a esta concepção, também está relacionado ao trabalho, à escolha de uma profissão.

Independentemente do lugar de onde falamos, são tempos de vida. Não há escola sem estudantes, assim como não há escolas sem professores. A escola, contudo, produz para cada pessoa sentidos e significados muito diversos, especialmente quando falamos em processos inclusivos.

E nesse sentido, colocamos em destaque a ressignificação da docência. É fundamental compreendermos que a educação brasileira, ao longo de sua história, constituiu-se a partir de um modelo que buscava a homogeneização dos estudantes. Assim, aspectos relacionados à reprovação e ao fracasso escolar foram naturalizados ao longo das trajetórias escolares, por meio das práticas pedagógicas (ARROYO, 2013, 2014).

De encontro a este modelo, os processos inclusivos fundam-se em uma perspectiva da heterogeneidade, da diversidade e do respeito aos tempos e modos de aprender. E essa nova realidade, quando assumida como um princípio institucional, exige mudanças estruturais, desde os espaços, os recursos humanos e o fazer dos professores como um todo. Se antes quem não aprendia era excluído, atualmente a premissa da educação inclusiva exige que a escola assuma o compromisso de favorecer os processos de aprender de todos os estudantes, reconhecendo e respeitando os ritmos e tempos de aprendizagens (WISCH, 2020).

Ou seja, o professor da sala de aula regular, que não está isento desse compromisso, precisa tornar-se um professor que ensina a todos os seus alunos. E é exatamente neste ponto que a tríade formativa, aqui proposta, ganha uma importância ímpar, pois os alunos que apresentam especificidades em seus processos de aprendizagem demandam novas formas de ensinar dos professores, os quais, por sua vez, necessitam de novas possibilidades formativas. "Talvez, pela primeira vez na história da formação docente brasileira, apresentam-se questões em que o foco deixa de ser os conteúdos e os métodos de ensino e passa a ser as especificidades dos próprios sujeitos educadores e educandos" (DINIZ-PEREIRA; LEÃO, 2008, p. 9).

Por isso mesmo, a formação de professores tornou-se ainda mais decisiva diante do paradigma inclusivo. A tríade formativa, defendida por este estudo, pressupõe que saberes, fazeres e compromissos estejam relacionados, encadeados, compondo a construção permanente do professor inclusivo. Defendemos a interdependência de cada elemento da tríade. É assim que os saberes, os fazeres e os compromissos se conectam num vaivém permanente, tanto durante os processos formativos quanto durante os processos experienciais. Isso porque defendemos também que a tríade depende tanto da formação permanente quanto da experiência, como processos que são individuais e coletivos ao mesmo tempo.

O conjunto de experiências com as quais os professores vão se deparando ao longo de sua trajetória profissional permite a construção de saberes que são próprios e que vão se modificando ao longo dessa trajetória. Podemos afirmar que há um entrelaçamento entre os saberes teóricos que os professores se apropriam na formação inicial e continuada com os saberes experienciais e cotidianos que são próprios de cada realidade (BOLZAN, 2001, 2009; BOLZAN; ISAIA, 2006). 
Posto isso, defendemos que o professor necessita ser compreendido como um profissional de saberes. Saberes teóricos e saberes práticos que se constroem a partir de uma prática reflexiva, que necessita estar alinhada com as demandas sociais e educacionais. Alguém que não possui um conhecimento estático, mas que está pautado em seus saberes e em todas as suas vivências, avançando junto com a sociedade.

E nessa direção, para concluirmos, sinalizamos mais um saber que perpassa a docência na perspectiva inclusiva - os saberes da diversidade (ARROYO, 2014, 2013). Quando pensamos nestes saberes, não estamos falando de um conjunto de informações sobre a diversidade, mas de uma docência pautada na formação humana, que compreende que é convivendo com a diferença que este saber nasce e se consolida, tanto para os estudantes envolvidos quanto para os professores.

\section{REFERÊNCIAS}

ALCADIPANI, Rafael. A academia e a fábrica de sardinhas. Organizações \& Sociedade, v. 18, n. 57, p. 345348, abr./jun. 2011.

ARROYO, Miguel González. Ofício de mestre: imagens e autoimagens. 15. ed. Petrópolis, RJ: Vozes, 2013. ARROYO, Miguel González. Imagens quebradas: trajetórias e tempos de alunos e mestres. 8 ed. Petrópolis, RJ: Vozes, 2014.

BOLZAN, Doris Pires Vargas. A construção do conhecimento pedagógico compartilhado: um estudo a partir de narrativas de professoras do Ensino Fundamental. 2001. Tese (Doutorado) - Universidade Federal do Rio Grande do Sul, Faculdade de Educação, Porto Alegre, 2001.

BOLZAN, Doris Pires Vargas. Formação de professores: compartilhando e reconstruindo conhecimentos. Porto Alegre, RS: Ed. Mediação. 2009.

BOLZAN, Doris Pires Vargas; ISAIA, Silvia Maria Aguiar. Aprendizagem docente na educação superior: construções e tessituras da professoralidade. Educação, v. XXIX, n. 3, p. 489-501, set./dez. 2006. Pontifícia Universidade Católica do Rio Grande do Sul Porto Alegre, Brasil.

CASTRA, Michel. Identité. In: PAUGAM, Serge. En Les 100 mots de la sociologie. Paris: PUF, 2010.

CUNHA, Celso Ferreira da; CINTRA, Luís Filipe Lindley. Nova gramática do português contemporâneo. Rio de Janeiro: Nova Fronteira, 2001.

DINIZ-PEREIRA, Júlio Emílio; LEÃO, Geraldo. Quando a diversidade interroga a formação docente. Belo Horizonte: Grupo Autêntica, 2008.

FREIRE, Paulo. Pedagogia da autonomia: saberes necessários à prática educativa. 45. ed. Rio de Janeiro, RJ: Paz e Terra, 2013.

GAUTHIER, Clermont. Por uma teoria da pedagogia. Pesquisas contemporâneas sobre o saber docente. 3. ed. Ijuí: Editora Unijuí, 2013.

GUIMARÃES, Orliney. M.; NAGATOMY, Gabrielly F. M. Representações sociais sobre a educação especial/ educação inclusiva: revisão da literatura (2008-2018): Revista Contexto \& Educação, v. 36, n. 114, p. 366385, 2021. DOI: https://doi.org/10.21527/2179-1309.2021.114.366-385

IMBERNÓN, Francisco. Formação continuada de professores. Porto Alegre, RS: Artmed, 2010.

LÓPEZ, Alejandra Montané. Compromisso e reconhecimento social dos professores: alguns paradoxos de uma profissão na encruzilhada. In: GIL, Juan Sancho; HERNÁNDEZ-HERNÁNDEZ, Fernando. Professores na Incerteza. Porto Alegre: Penso, 2016.

MAYO, Isabel Cantón; TARDIF, Maurice. Identidad professional docente. Madrid, Espanha: Narcea Ediciones, 2018.

MENDONÇA, Ana Abadia dos Santos. Educação Especial e Educação Inclusiva: dicotomia de ensino dentro de um mesmo processo educativo. In: ENCONTRO DE PESQUISA EM EDUCAÇÃO, 8., 2015. Uberaba. Anais [...]. Uberaba: Universidade de Uberaba, 2015.

MOYSÉS, Maria Aparecida Affonso. A institucionalização invisível: crianças que não-aprendem-na-escola. 2. ed.. Campinas: Mercado das Letras, 2014. 
PAZ, Cláudia Terra do Nascimento; CRUZ, Yara da Rocha. "O receio de ser igual em meio às diferenças": reflexões acerca do antagonismo existencial dos professores do Ensino Médio diante da inclusão escolar. Cadernos do Aplicação, Porto Alegre: UFRGS, Seção Temática Especial: Educação Especial e Processos Inclusivos, 2021.

PAZ, Cláudia Terra do Nascimento; SOARES, Graciele Rosa da Costa. Adaptações curriculares para alunos com dificuldades específicas de aprendizagem: possibilidades para um processo inclusivo. In: SONZA, Andréa Poletto; SALTON, Bruna Poletto; DALL AGNOL, Anderson. Reflexões sobre o currículo inclusivo. Bento Gonçalves, RS: Instituto Federal de Educação, Ciência e Tecnologia do Rio Grande do Sul, 2018.

PLETSCH, Marcia Denise; SOUZA, Flávia. Faissal; ORLEANS, Luis Fernando. A diferenciação curricular e o desenho universal na aprendizagem como princípios para a inclusão escolar. Revista Educação e Cultura Contemporânea, v. 14, n. 35, 2017.

RIGO, Neusete M. Desdobramentos da Política Nacional de Educação Especial na perspectiva da educação inclusiva em políticas locais. Revista Contexto \& Educação, v. 31, n. 100, p. 187-213, 2017. DOI: https://doi.org/10.21527/2179-1309.2016.100.187-213

SCHOMMER, Paula Chies; FRANÇA FILHO, Genauto Carvalho. A metodologia da residência social e a aprendizagem em comunidades de prática. In: FISCHER, Tania; ROESCH, Sylvia; MELO, Vanessa Paternostro (org.). Gestão do desenvolvimento territorial e residência social: casos para ensino. Salvador: Edufba; Ciags; Ufba, 2006. p. 63-82.

SONZA, Andréa Poletto; SALTON, Bruna Poletto; DALL AGNOL, Anderson. Reflexões sobre o currículo inclusivo. Bento Gonçalves, RS: Instituto Federal de Educação, Ciência e Tecnologia do Rio Grande do Sul, 2018. TARDIF, Maurice. Saberes docentes e formação profissional. Petrópolis, RJ: Vozes, 2002.

ULLIANE, Carla. Como elaborar um Plano Educacional Individualizado. 2016. Disponível em: https://carlaulliane.com/2016/plano-educacional-individualizado-como-elaborar-um-pei/. Acesso em: 24 ago. 2021. VYGOTSKI, Lev Semenovitch. A formação social da mente: o desenvolvimento dos processos psicológicos superiores. 7. ed. São Paulo, SP: Martins Fontes, 2007.

WISCH, Tásia Fernanda. Contextos emergentes no Colégio de Aplicação: tessituras das docências na perspectiva inclusiva. 2020. 272 f. Tese (Doutorado em Educação) - Universidade Federal de Santa Maria, Programa de Pós-Graduação em Educação, Centro de Educação, Santa Maria, 2020. 